\title{
MILAN JESIH
}

Poeta, dramaturgo y traductor Milan Jesih nació el 14 de abril de 1950. Estudió Literatura comparada en Ljubljana. Ha sido miembro del grupo vanguardista 442 . Vive en Ljubljana.

Su primer libro de poesía se publica en el año 1972 bajo el título Uran v urinu, gospodar! ( Uranio en la orina, señor!). A éste le siguen: Legende (1974, Leyendas), Kobalt (1976, Cobalto), Volfram (1980, Volframio), Usta (1985, Boca), Soneti (1989, Sonetos), Soneti drugi (1993, Sonetos segundos). Su poesía se basa en los juegos de palabras, sonoridad enfatizada, ironía, sátira y parodia, sus últimos libros de poesía estan dedicados al soneto.

La presente selección pertenece al ya clásico Soneti (Sonetos). Los poemas han sido previamente publicados en Antología de la Poesía eslovena contemporánea, Ljubljana, 1995.

Traducción: Antonio Preciado Bernal y Barbara Pregelj. 


\section{SONET I}

Nocoj to uro se mi zdi življenje, kakršno je bilo - ljudje, imena, dotiki, vonji - samo pozabljenje, ves moj spomin pa pust spomin kretena.

Smeh pomnim, pomnim solze, tiho hvalo, ki sem naklanjal jo ljubim jo ljudem ljubezni same pa ni nič ostalo:

spomin ni gluh ne slep, vendar je nem.

Od svojih zdaj imam samo grobove. Še vem, da so me smrti prizadele, a sveče $\mathrm{v}$ pišu časa dogorele

feniksi niso, da bi vstale nove; podobe prejšnjih dni so prazna usta vsej lakoti, da bi obudil čustva. 


\section{SONETOS}

I

Esta noche a esta hora me parece lo vivido como ha sido - los nombres, cada ser vecino, los tactos, los olores- solamente olvido, $\mathrm{y}$ todos mis recuerdos, recuerdos de un cretino.

Recuerdo risas, lágrimas, el callado halago que dedicaba yo a la gente mía amable; del amor mismo todo luego se hizo vago: El recuerdo no es ciego ni sordo, aunque no hable.

Hoy de los míos ya tengo tumbas solamente. Que sus muertes me dolieron, lo sé todavía, mas las velas que el tiempo, brisa, amató un día,

Fénix no son, para hoy volver a ser presente.

La imagen del pasado le sabe a boca vacía a esta hambre mía de evocar lo que sentía. 
Mož svežeporočen pod oknom svoje lepe izvoljenke, device mlade, $\mathrm{z}$ dehtečim glasom in ob lutnji poje neubranljivo strastne serenade,

vse uglašene, kajpada, na temo ljubezni, Amorja, nežnih poljubov, cvetečih lic, vzkipelih prsi $-z$ vnemo, ki vodi gladko in samo $v$ pogubo.

Najprej se mu smehljala je $z$ balkona, več ne prikaže se od polnoči;

svatje so godrnjaje se razšli;

in stara dva obliva mrzla zona ne sredstvo, pesem mu je sama cilj, dani se, pa prepeva še vsevdilj. 
Un hombre recién casado bajo la ventana de una doncella joven, su bella amada, con su temblorosa voz, sobre un laúd hilvana serenatas irresistibles por lo apasionadas, todas ellas, claro está, afinadas sobre el tema del amor, del Amor, del amor, con besos tiernos, rostros en flor, pechos ardientes, fuego que quema, que le lleva sólo, directamente a los Infiernos.

Primero sonreía desde su alto balcón, mas ya no aparecía a partir de medianoche, invitados murmurando, pidiendo un coche,

los padres abochornados por la situación. Su propio fin, no un medio, es esta su canción, y sin cesar, sin fin, canta el lírico anfitrión. 
III

Nekoč nekje ob vodi mirujoči, najbržda jezeru - in mesec mlad bo šele pozno vzšel, a do takrat le iz teme tema $v$ temo se toči dva ljubita se gola v vlažni travi. Poljub, ki jeden je, a ne ogrize; objem, ki stisne, vendar ne zadavi; nočni obed — užit brez žlic in mize!

Nad njima lahno prišumeva listje, piš oblizuje z gorke kože znoj, nedoumljivo čas pozoren, čist je,

je Zmerom, ki mu je ime Nocoj, povsodni, tu edinole navzoč: ob tihem jezeru, nekje, nekoč. 
Érase una vez que se era junto al agua pura, casi intocable, quieta, - - la joven luna va a salir muy tarde, mas, mientras no hay ninguna, de oscuro a oscuro corre oscuridad oscura.-

Dos se aman desnudos sobre la yerba mojada. Se come, pero no muerde, el beso que besa, lo aprieta todo este abrazo, pero no ahoga nada, banquete crepuscular - isin cucharas ni mesa!

Las hojas leves susurran suaves sobre ellos, la brisa lame sudor de la piel, que es llama, incomprensiblemente, son instantes claros, bellos, son tiempo limpio, es Siempre, que Ahora se llama, omnipresente, mas lo encontrarás sólo a la vera del callado lago, érase una vez que se era. 
O, srečnik, ki si ubil očeta Laja!

$\mathrm{Z}$ enim udarcem, pof, ga samosilnik precizno si pomeril na zatilnik; Jokasto, lastno mater pa nasajal

do jutra marsikatero znojno noč, da se je trd kraljevski špampet majal ti sin očetomorni, mamin mož, otrokom svojim brat, torej odhajaš.

Slast si užil, danes gorja nič manj. Bogato obdarjen greš: slep in strt iz Teb ta beli izplačilni dan

in z zadoščenjem, da bolj niti smrt človeka ne zašpili, proč poslan: malo še živ, a ves že dokončan. 
Oh, afortunado, que mataste a Layos, tu padre, tú, soloentrometido, crac, de un golpe nada más, acertaste a partirle el cuello por detrás y te follabas a Yokasta, tu propia madre

muchas sudorosas noches, hasta amanecido, en que la dura cama se movía, real, tú hijo parricida, de tu madre marido, hermano de tus hijos, que después te irás.

Disfrutaste el placer, hoy no menos dolor llevas. Con buena herencia: ciego y triste te vas en este día, blanco de pago, de tu Tebas

y con satisfacción, que ni siquiera morir, más le jode al hombre que ser exiliado lejos un poco vivo aún, mas ya acabado y viejo. 
Veter podi čez trg star časopis.

$\mathrm{Na}$ nebu zbirajo se k jugu jate:

po sivem beg nemirnih sivih lis.

Ljudje ste $v$ parih, radi se imate,

za roke greste tiho skozi jesen, kot bi zamišljeni prišli od maše. Za pičel čas zaton temno ognjen preškrlati starinsko mesto vaše,

a prvi hip noči iz vseh strani se bližati začutijo daljave:

brezglav poplah, češ, mili Bog, boli!

in mrejo v sladkih vonjih trepetave.

Potem, usojen, da nikdar ne mine, se vzdigne dolg, brezkončen pisk tišine. 
Por la plaza el viento arrastra un periódico viejo.

En el cielo se juntan al sur las bandadas:

sobre el gris, grises manchas inquietas, huyen lejos,

la gente sois parejas, de dos en dos se ama,

de la mano vais silenciosos por el otoño, como quienes vuelven de una misa pensativos, por un momento fuera declina un negro tono, vuestra ciudad se tiñe de escarlata vivo,

pero, en el primer momento de la noche, sienten acercarse desde todas partes lejanías:

pánico aturdido, ipor Dios, que duele!

y en dulce olor, temblerosos, caen en agonía.

Lo que no ha de ser, la suerte lo ha decidido, del silencio retumba el infinito pitido. 